\title{
Introduction: Recent developments in cyanobacterial research with special reference to aquatic habitats, molecular ecology and phylogenetic taxonomy
}

\author{
Eugen Rott $\cdot$ Allan Pentecost $\cdot$ Jan Mareš
}

Received: 29 November 2017/Revised: 29 November 2017/Accepted: 9 December 2017/Published online: 14 February 2018

(C) The Author(s) 2018. This article is an open access publication

\begin{abstract}
The global importance of cyanobacteria is well known from their worldwide distribution and abundance as well as their contribution to atmospheric oxygen. In spite of a long history of cyanobacterial research in microbiology and botany, only a small portion of their high diversity has been recovered and only recently been addressed by
\end{abstract}

Electronic supplementary material The online version of this article (https://doi.org/10.1007/s10750-017-3468-9) contains supplementary material, which is available to authorized users.

Guest editors: Eugen Rott, Allan Pentecost \& Jan Mares / Aspects of cyanobacterial biogeography, molecular ecology, functional ecology and systematics

\section{E. Rott ( $\bowtie)$}

Institute of Botany, University of Innsbruck, Sternwartestrasse 15, 6020 Innsbruck, Austria e-mail: eugen.rott@uibk.ac.at

\section{A. Pentecost}

Freshwater Biological Association, Ferry Landing,

Ambleside LA22 0LP, UK

J. Mareš

The Czech Academy of Sciences, Biology Centre, Institute of Hydrobiology, Na Sádkách 7, 37005 Ceske Budejovice, Czech Republic

\section{J. Mareš}

Faculty of Science, Department of Botany, University of South Bohemia, Branišovská 1760, 37005 Ceske

Budejovice, Czech Republic molecular and phylogenetic methods. Controversies in traditional and modern approaches to cyanobacterial taxonomy still persist, which has stimulated their discussion within the 20th IAC Symposium. In this special section, we present a set of nine contributions, selecting the most interesting outcomes of the meeting. The molecular approaches applied deal on one hand, with classical single and multilocus phylogenetic taxonomy methods, on the other hand with high-throughput next generation sequencing methods to rapidly identify diversity of cyanobacteria in environmental samples without the possibility to investigate their taxonomic status in depth. The studied ecosystems include a variety of freshwater, brackish and marine, planktonic and benthic habitats from which cyanobacteria were sampled. Study regions comprise temperate, arctic, alpine and tropical environments from four continents. We discuss the salient points of the contributions from this volume and formulate four main issues from which conclusions are drawn in order to contribute to future progress in cyanobacterial research.

Keywords Cryptic diversity - Cyanobacteria · Ecology · Genomes · Morphology · 16S rRNA gene 


\section{Introduction}

Cyanobacteria or Blue-Green Algae are photosynthetically active (pigmented) oxygenic bacteria with a world-wide distribution which is well known to have contributed essentially to the creation of the oygenation of the Earth's atmosphere (Kasting \& Siefert, 2002) and is estimated today to contribute up to $50 \%$ of the ocean's primary productivity (Falkowski, 2012). In relation to the site of the meeting, Innsbruck, a major city in the heart of the Eastern Alps, the focus proposed for the 20th IAC Symposium $^{1}$ was on cyanobacteria in alpine and arctic habitats linking the geo- and hydrosphere. It included snow and ice, subaerial rock and soil habitats as well as springs, rivers and lakes with a focus on mountain and glacial streams, littoral shores of lakes and the sea. The rationale of cyanobacterial studies in general is given by the fact that these organisms comprise important bioindicators to identify environmental quality (Mateo et al., 2015; Monteguardo, 2016) as well as important producers of toxins (Dittmann et al., 2013) and other secondary metabolites which are currently used for the biosynthesis of biotechnological (Abed et al., 2009; Ducat et al., 2011) and pharmaceutical products (Vijajacumar \& Mengakha, 2015).

More than 70 scientists from 21 nations and five continents attended the 20th IAC Symposium and presented 30 oral and 27 poster contributions arranged within five session topics: Functional molecular biology and phylogeny, biogeography, systematics and taxonomy, biocalcification, and functional ecology and biodiversity (Rott, 2016). The meeting provided a forum for discussion of the merits and value of molecular vs classical taxonomy of cyanobacteria. Up to the second half of the twentieth century, the only available method of describing species, and distinguishing between them was their size and morphology (Geitler, 1932). It was already known that cyanobacteria brought into culture often changed their morphology but the reasons were unknown and their implications largely ignored by taxonomists. To overcome these difficulties, in the

\footnotetext{
${ }^{1}$ Scientific meetings are held every third year and organized by the International Association for Cyanophyte/Cyanobacteria research (IAC), a group of international scientists founded in 1958 in Austria in order to optimize standards of taxonomic and ecological studies of this prokaryotic group of photosynthetic oxygenic organisms.
}

last several decades, it has been proposed to base the taxonomy and identification of cyanobacterial species on standardized and (putatively) stable genetic markers (Edelman et al., 1967). Using the SSU rRNA gene (Hoffmann et al., 2005), and more recently multiple conserved genes (Komárek, 2017), most of the recent studies have endeavoured to harmonize the classical morphological taxonomy with the results of phylogenetic studies (Johansen \& Casamatta, 2005). Nevertheless, numerous traditional taxa have been recognized to exhibit extreme polyphyly, in particular due to homoplasy caused by serial convergence events (Dvořák et al., 2014). These findings have led to an explosion of newly described taxa (Komárek, 2017), including cryptic ones (Osorio-Santos et al., 2014). An alternative "bacteriological" treatment of cyanobacterial diversity has relied on detailed examination of pure strains, including the analysis of complete genomes (Castenholz, 2001; Shih et al., 2013). The latter approach seems to better suit the bacterial nature of the studied organisms; however, it has thus far failed to propose a solution for their modern taxonomic treatment. The sometimes bifurcated view of cyanobacterial taxonomy has been reflected in the chronically unsolved problems in cyanobacterial nomenclature, which currently has an unclear standing under the International Code of Nomenclature of Prokaryotes (Parker et al., 2015), and is mainly governed by the International Code of Nomenclature for Algae, Fungi, and Plants (McNeill et al., 2012), as recently summarized by Oren \& Ventura (2017). The modern standards for the description of cyanobacterial taxa, and especially the possible solutions of the problems regarding nomenclatural rules were extensively discussed during round-table discussions at the 20th IAC meeting, and are planned to be published in future following further comprehensive debate among specialists. The fact that cyanobacterial taxonomy is in the middle of vigorous change presents a barrier for successful application of next generation sequencing (NGS) methods to investigate the biodiversity of cyanobacteria. The assignment of taxa to sequences is often a challenge in molecular-based classification methods applied to environmental samples (Ramos et al., 2017). The studies published within the current special section have attempted to move forward some of the issues mentioned above and provide future prospects for research in cyanobacterial 
taxonomy, ecology and biogeography employing a combination of classical and modern methods.

\section{Results}

The thematic clusters of contributions in this special section (Supplementary Table 1) comprised the following: (i) problems and developments of the polyphasic evaluation of cyanobacterial biodiversity on the generic and suprageneric levels (Komárek, 2017; Mareš, 2017), and on the infrageneric level (Kurmayer et al., 2017; Rigonato et al., 2017), based on phylogenetic taxonomy; (ii) implementation of the results of modern taxonomic surveys into practical applications such as floristic and environmental research (Davydov \& Patova, 2017; Komárek, 2017); (iii) molecular and morphological diversity and adaptation of taxa and/or OTUs to special environments and niches assessed by next-generation sequencing (Palinska et al., 2017; Ruber et al., 2017; Vogt et al., 2017); and (iv) occurrence of specific morphospecies and communities linked to and regulated by specific environmental characteristics in biocalcified lowland streams (Pentecost, 2017), alpine streams (Kurmayer et al., 2017), stratified freshwater lakes (Ruber et al., 2017), and marine tidal flats (Vogt et al., 2017). The main merits and the taxonomic and biogeographic scope of the individual contributions are summarized in Online Supplemental Table 1 .

Recent developments in molecular phylogeny and polyphasic taxonomy of cyanobacteria

Since cyanobacteria are prokaryotes, their evolutionary processes and inheritance of features follow the specific rules and conditions of bacteria such as the absence of sexual reproduction and the large extent of horizontal gene transfer and homologous recombination (Dvořák et al., 2015). Progress in the evolutionary study of cyanobacteria was to some extent hindered by the exclusive use of the SSU rRNA gene by most researchers so that the actual number of available genomes and multilocus or phylogenomic studies has been until recently restricted. These facts are addressed in the contribution by Mareš (2017). The study provides a direct comparison of SSU rRNA and multilocus phylogenies based on the actual set of available cyanobacterial genomes. The results should help other researchers to anchor their rRNA phylogenies in the cyanobacterial system and provide a possible baseline for future genome-based taxonomy of cyanobacteria. Although Mareš (2017) presents a robust phylogeny of the major cyanobacterial lineages based on 23 conserved proteins encoded in all the analysed genomes, the conserved markers used in his study are not applicable for delimitation of closely related cyanobacterial species. Apparently, one of the best known genomic regions suitable for species level taxonomy is the rRNA internal transcribed spacer (ITS), as exemplified in the contribution by Rigonato et al. (2017). The $16 \mathrm{~S}$ rRNA gene sequencing of the previously morphologically defined genus of planktic cyanobacteria Sphaerocavum have brought evidence for its identity with Microcystis, while detailed analysis of the rRNA ITS data suggested that it was a separate species within this genus. Another study focused on a single genus, Chamaesiphon, where a reproducible protocol for single-colony sequencing of epilithic cyanobacteria in streams was developed (Kurmayer et al., 2017). The SSU rRNA data obtained in that study did not allow any firm conclusions regarding the present species as the morphology and ultrastructure data were not congruent with the reconstructed phylogeny. The current trends in the polyphasic taxonomic assessment of cyanobacteria as a whole group, with particular reference to several important taxa, were further discussed in Komárek (2016, 2017).

Application of the modern cyanobacterial taxonomy in field-based and environmental research

Because the monophyletic origin of the traditionally used identification features is rarely achieved in cyanobacteria, and the modern taxonomy perceives monophyly of taxa as a fundamental necessity, continuous updating of taxonomic categories is unavoidable. This may cause problems for research in applied and environmental sciences, nature conservation and water quality monitoring, since an ambiguous identification makes any bioindication system unworkable resulting in a lack of compatibility between different labs, countries and continents. One solution to this problem is possible by the quick 
adaptation of online databases from regional and extra-regional internet platforms (e.g. CYANOpro; CyanoDB, AlgaeBase). Being open access, they provide an improved tool for the environmentalists and other specialists seeking the current taxonomic updates, species lists, and catalogues from different regions and habitats. The contribution by Davydov \& Patova (2017) has listed over 600 cyanobacterial species from about 1500 locations in the Eurasian Arctic and Hypoarctic in the CYANOpro database ( http://kpabg.ru/cyanopro/) making it an excellent resource for further research in this area. Another way of maintaining the awareness of the recent taxonomic changes is regular publication of reviews that explain the current criteria for definition of taxa and summarize the most important changes. The review contribution by Komárek (2017) provides such a summary and discusses in detail the terms morphospecies, cryptospecies, and ecospecies in the framework of the polyphasic approach. Komárek (2017) also once again points out the necessity to use valid nomenclatural types as the basis for definition of cyanobacterial taxa.

Application of next-generation sequencing to microbial communities to study biodiversity and niche adaptation in cyanobacteria

NGS of environmental communities produces useful information on their biodiversity; however, the interpretation of data and their relationship to the actual living organisms and the relative dominance of taxa can be a difficult undertaking. The identification of taxa is further limited by the comparatively low number of sequenced base-pairs and by the presence (or absence) of highly similar sequences in reference databases. The model of OTUs (Operational Taxonomic Units) for the unicellular picocyanobacterium Synechococcus in perialpine lakes has been successfully applied to seasonal data from Bavaria (Ruber et al., 2017), although Synechococcus is a polyphyletic taxon. For the tidal flats of the Baltic reproducible information on the dominant genera could be successfully identified and insights to the patch diversity in space and time was obtained by Vogt et al. (2017). NGS data from the Blue Lagoon (Palinska et al., 2017) gave some insights in specific key taxa of cyanobacteria in a volcanic silica-rich brackish thermal pool of Iceland, providing an example of a metagenomic study in a previously neglected type of extreme habitat.

Investigation of ecological traits within cyanobacterial communities at the species level

The role of dissolved organic and inorganic phosphates in streams containing calcified cyanobacterial communities dominated by Phormidium incrustatum (Naegeli) Gomont was explored by Pentecost (2017). In calcified cyanobacteria, phosphate can be taken up by both the cyanobacteria and the deposited calcite, but when inorganic phosphate concentrations exceed a critical level, calcite deposition is inhibited and calcification no longer occurs. So many English waters contain high concentrations of phosphate that they can no longer support these calcifying communities, and in those that do contain them, the phosphorus taken up by the calcite does not appear to be available to the associated cyanobacteria.

For Chamaesiphon in streams of Austria, specific traits were found to be related to distinct morphospecies. However, the results could not be verified by the single-colony environmental sequencing of the SSU rRNA gene due to its high infrageneric variability (Kurmayer et al., 2017), although Chamaesiphon still turned out as a monophyletic genus. Other ecological traits for marine tidal flats included sediment patch analysis based on sandy shore depth profiling. Next generation sequencing results were related to morphological and SEM studies of key taxa mainly at the genus level in this study (Vogt et al., 2017). New information on the ecological niche for individual species-like Synechococcus OTUs was gained from stratified lake profiling during the main key seasons (Ruber et al., 2017).

\section{Conclusions}

Based on the contributions presented in this special section, we offer the following remarks and ask new research questions that may contribute to future development of cyanobacterial studies integrating classical phycological, microbiological and fieldbased investigations with advanced molecular methods. 
- Field-based biodiversity studies are still required due to the fact that the current knowledge on cyanobacteria taxa richness worldwide remains relatively restricted (around 50\% of species are left to be described according to recent estimates —Nabout et al., 2013). However, major progress can only be reached by integration of field observations that report ecotypes adapted to a specific habitat with analysis of derived laboratory strains that allow evaluation of phenotype plasticity during the life cycle and at varied cultivation conditions while linking it to a stable genotype.

- Frequent convergence on one side and morphological plasticity on the other side observed in cyanobacterial taxa at all levels requires continued taxonomic work focused on detection of homoplasy and cryptic diversity. Utilizing the rapidly growing database of genomic data may help achieve monophyly and may also assist on the level of orders and families in the foreseeable future.

- Morphological and ultrastructural studies are strongly suggested as a useful complement to laboratory investigations based on strains (e.g. biochemical analyses, large-scale DNA sequencing) (see also Willmotte et al., 2017).

- In ecological studies, single cell- or colony-based approaches are applicable to a variety of cyanobacteria that resist cultivation. These techniques are useful for molecular identification and barcoding of special morphotypes (ecomorphs) that are manifested exclusively under natural conditions, plus their phenotype plasticity assessment, and ecological niche estimation.

- Comprehensive databases integrating gene libraries with detailed iconography and ecological information on taxa and strains have a potential to improve the publicly shared knowledge on cyanobacteria and reduce not only taxonomic and nomenclatoric confusion but also contradictions and incompatibilities among different labs/ researchers.

- Cyanobacterial populations occupying specific niches in the environment and forming the key components of distinct microbial communities (e. g. macroscopic biocalcified mats, epilithic growths in streams) require development of new specific molecular markers with high resolution to enable understanding of their genetic identity and the identification of niche-specific ecotypes (ecomorphs). Elucidation of functional genes connected with species-specific traits and tracking of their expression is necessary to make progress in understanding the ecological roles of cyanobacterial components of microbial communities and consortia.

Acknowledgements Open access funding provided by University of Innsbruck and Medical University of Innsbruck. We thank all the Hydrobiologia editors and their collaborators for producing the present collection of papers from the 20th IAC Symposium. We gratefully acknowledge all referees and editors which have assisted in the reviewing process of the manuscripts as well as the staff of Springer for producing it. We thank all the authors and hope that this set of papers will have impact into the new concepts and developments in cyanobacteria research.

Open Access This article is distributed under the terms of the Creative Commons Attribution 4.0 International License ( http://creativecommons.org/licenses/by/4.0/), which permits unrestricted use, distribution, and reproduction in any medium, provided you give appropriate credit to the original author(s) and the source, provide a link to the Creative Commons license, and indicate if changes were made.

\section{References}

Abed, R. M. M., S. Dobretsov \& K. Sudesh, 2009. Application of cyanobacteria in biotechnology. Journal of Applied Microbiology 106: 1-12.

Castenholz, R. W., 2001. Phylum BX. Cyanobacteria. In Boone, D. R. \& R. W. Castenholz (eds), Bergey's manual of systematic bacteriology. Springer, New York: 473-599.

Davydov, D. \& E. Patova, 2017. The diversity of Cyanoprokaryota from freshwater and terrestrial habitats in the Eurasian Arctic and Hypoarctic. Hydrobiologia. https://doi.org/10.1007/s10750-017-3400-3.

Dittmann, E., D. P. Fewer \& B. A. Neilan, 2013. Cyanobacterial toxins: biosynthetic routes and evolutionary roots. FEMS Microbiology Reviews 37: 23-43.

Ducat, D. C., J. L. Way \& P. A. Siver, 2011. Engineering cyanobacteria to generate high-value products. Trends in Biotechnology 29: 95-103.

Dvořák, P., D. A. Casamatta, A. Poulíčková, P. Hašler, V. Ondřej \& R. Sanges, 2014. Synechococcus: 3 billion years of global dominance. Molecular Ecology 23(22): 55385551.

Dvořák, P., A. Poulíčková, P. Hašler, M. Belli, D. A. Casamatta \& A. Papini, 2015. Species concepts and speciation factors in cyanobacteria, with connection to the problems of diversity and classification. Biodiversity and Conservation 24: 739-757. 
Edelman, M., D. Swinton, J. A. Schiff, H. D. Epstein \& B. Zelden, 1967. Deoxyribonucleic acid of the blue-green algae (Cyanophyta). Bacteriological Revue 31: 315-331.

Falkowski, P., 2012. The power of plankton. Do tiny floating microorganisms in the ocean's surface waters play a massive role in controlling the global climate? Nature 483: 17-20.

Geitler, L., 1932. Cyanophyceae. In Rabenhorst, L. (ed), Kryptogamen-Flora von Deutschland, Österreich und der Schweiz. Ed. 2. Vol. 14. Akademische Verlagsgesellschaft, Leipzig: 673-1196.

Hoffmann, L., J. Kaštovský \& J. Komárek, 2005. System of Cyanoprokaryotes (Cyanobacteria) - state in 2004. Algological Studies/Archiv für Hydrobiologie, Supplement Volumes 117: 95-115.

Johansen, J. R. \& D. A. Casamatta, 2005. Recognizing cyanobacterial diversity through adoption of a new species paradigm. Algological Studies/Archiv für Hydrobiologie, Supplement Volumes 117: 71-93.

Kasting, J. \& J. L. Siefert, 2002. Life and evolution of the earth's atmosphere. Science 296: 1066-1068.

Komárek, J., 2016. A polyphasic approach for the taxonomy of cyanobacteria: principles and applications. European Journal of Phycology 51: 346-353.

Komárek, J., 2017. Several problems of the polyphasic approach in the modern cyanobacterial system. Hydrobiologia. https://doi.org/10.1007/s10750-017-3379-9.

Kurmayer, R., G. Christiansen, A. Holzinger \& E. Rott, 2017. Single colony genetic analysis of epilithic stream algae of the genus Chamaesiphon spp. Hydrobiologia. https://doi.org/10.1007/s10750-017-3295-z.

Mareš, J., 2017. Multilocus and SSU rRNA gene phylogenetic analyses of available cyanobacterial genomes, and their relation to the current taxonomic system. Hydrobiologia. https://doi.org/10.1007/s10750-017-3373-2.

Mateo, P., F. Legane's, E. Perona \& V. Loza, 2015. Cyanobacteria as bioindicators and bioreporters of environmental analysis in aquatic ecosystems. Biodiversity \& Conservation 24: 909-948.

McNeill, J., F. R. Barrie, W. R. Buck, V. Demoulin, W. Greuter, D. L. Hawksworth, P. S. Herendeen, S. Knapp, K. Marhold, J. Prado, W. F. Prud'homme van Reine, G.F. Smith, J. H. Wiersema \& N. L. Turland (eds), 2012. International Code of Nomenclature for algae, fungi, and plants (Melbourne Code) adopted by the Eighteenth International Botanical Congress Melbourne, Australia, July 2011. Regnum Vegetabile 154. Koeltz Scientific Books, Koenigstein.

Monteguardo, J. L. M., 2016. Benthic freshwater cyanobacteria as indicators of anthropogenic pressures. Ecological Indicators 67: 693-702.

Nabout, J.C., B. da Silva Rocha, F. M. Carneiro \& C. L. Sant' Anna, 2013. How many species of Cyanobacteria are there? Using a discovery curve to predict the species number. Biodiversity and Conservation 22: 2907-2918.

Oren, A. \& S. Ventura, 2017. The current status of cyanobacterial nomenclature under the "prokaryotic" and the "botanical" code. Antonie Van Leeuwenhoek 110(10): 1257-1269.
Osorio-Santos, K., N. Pietrasiak, M. Bohunická, L. H. Miscoe, L. Kováčik, M. P. Martin \& J. R. Johansen, 2014. Seven new species of Oculatella (Pseudanabaenales, Cyanobacteria): taxonomically recognizing cryptic diversification. European Journal of Phycology 49: 450-470.

Palinska, K. A., J. C. Vogt \& W. Surosz, 2017. Biodiversity analysis of the unique geothermal microbial ecosystem of the Blue Lagoon (Iceland) using next-generation sequencing (NGS). Hydrobiologia. https://doi.org/ 10.1007/s10750-017-3349-2.

Parker, C. T., G. M. Garrity \& B. J. Tindall, 2015. International Code of Nomenclature of Prokaryotes. Prokaryotic Code. 2008 Revision. Published for the International Committee on Systematics of Prokaryotes. https://doi.org/10.1099/ ijsem.0.000778, Accessed 20 Nov 2015. (in press).

Pentecost, A., 2017. Cyanobacteria-phosphate-calcite interactions in limestone (hardwater) streams of England. Hydrobiologia. https://doi.org/10.1007/s10750-017-3280-6.

Ramos, V. M. C., R. Castelo-Branco, P. N. Leão, J. Martins, S. Carvalhal-Gomes, F. Sobrinho da Silva, J. G. Mendonça Filho \& V. M. Vasconcelos, 2017. Cyanobacterial Diversity in Microbial Mats from the Hypersaline Lagoon System of Araruama, Brazil: an In-depth Polyphasic Study. Frontiers in Microbiology 8: 1233.

Rigonato, J., C. L. Sant'Anna, A. Giani, M. T. P. Azevedo, A. G. Watson, F. L. Valquiria, V. M. F. Fiore \& V. R. Werner, 2017. Sphaerocavum: a coccoid morphogenus identical to Microcystis in terms of $16 \mathrm{~S}$ rDNA and ITS sequence phylogenies. Hydrobiologia. https://doi.org/ 10.1007/s10750-017-3312-2.

Rott, E., 2016. (ed.) 20th Cyanophyte/Cyanobacteria Research Symposium. Program \& Abstracts Volume. Institute of Botany, University of Innsbruck, 78 pp. ISBN 978-39500090-6-4.

Ruber, J., J. Geist, M. Hartmann, A. Millard, U. Raeder, M. Zubkov \& K. Zwirglmaier, 2017. Spatio-temporal distribution pattern of the picocyanobacterium Synechococcus in lakes of different trophic states: a comparison of flow cytometry and sequencing approaches. Hydrobiologia. https://doi.org/10.1007/s10750-017-3368-z.

Shih, P. M., D. Wu, A. Latifi, S. D. Axen, D. P. Fewer, E. Talla, A. Calteau, et al., 2013. Improving the coverage of the cyanobacterial phylum using diversity-driven genome sequencing. Proceedings of the National Academy of Sciences USA 110: 1053-1058.

Vijayakumar, S. \& M. Menakha, 2015. Pharmaceutical applications of cyanobacteria. A review. Journal of Acute Medicine 5: 15-23.

Vogt, J. C., D. C. Albach \& K. A. Palinska, 2017. Cyanobacteria of the Wadden Sea: seasonality and sediment influence on community composition. Hydrobiologia. https://doi.org/10. 1007/s10750-017-3287-z.

Willmotte, A., H. D. Laughinghouse, C. Capelli, R. Rippka \& N. Salmaso, 2017. Taxonomic identification of cyanobacteria by a polyphasic approach. In: Kurmayer, R., K. Sivonen, A. Willmotte \& N. Salmaso (eds), Molecular Tools For The Detection And Quantification Of Toxigenic Cyanobacteria. Wiley, Hoboken: 79-119. 